\title{
Bat conservation in China: should protection of subterranean habitats be a priority?
}

\author{
Jinhong Luo, Tinglei Jiang, Guanun Lu, Lei Wang, Jing Wang and Jang Feng
}

\begin{abstract}
Subterranean environments are essential for the survival of many bat species and other cave fauna but these places are subject to increasing human disturbance. To examine the significance of subterranean habitats for the conservation of bats in China we surveyed bat species in 225 underground sites during 2003-2011. Our results show that $77 \%$ of bat species in China, including 30 nationally Endangered or Vulnerable species and nine endemic species, roost in caves and other subterranean habitats. The number of species in occupied roosts was 1-15. Almost $90 \%$ of the roosts surveyed contained signs of human disturbance, most of which was from recreational activities. One hundred and twenty-one roosts merit special concern because they harbour $\geq 6$ species or $>1,000$ individuals, or species of special concern (threatened or endemic species). Generally, larger roosts support more species and a greater abundance of bats than smaller roosts but there is no direct correlation between the presence of species of special concern and roost size. Disused tourist caves have significantly more bat species than other types of roosts. Our data demonstrate that roost disturbance by recreational activities has pronounced detrimental effects on the number of bat species and the presence of species of special concern. We discuss the social, economic and political issues that could adversely affect bat conservation in caves in China, and we recommend that protection of subterranean habitats should be a high priority for bat conservation.
\end{abstract}

Keywords Bats, China, Chiroptera, conservation priority, endemism, human disturbance, species richness, tourist cave

This paper contains supplementary material that can be found online at http://journals.cambridge.org

\section{Introduction}

$\mathrm{B}$ ats are ecologically important as pollinators, seed B dispersers and insect predators (Cleveland et al., 2006; Betke et al., 2008; Kalka et al., 2008; Lobova et al., 2009;

Jinhong Luo, Tinglei Jiang, Guanjun Lu, Lei Wang, Jing Wang and Jiang FeNG (Corresponding author) Jilin Key Laboratory of Animal Resource Conservation and Utilization, Northeast Normal University, 5268 Renmin Street, Changchun, 130024, China, and Key Laboratory for Wetland Ecology and Vegetation Restoration of National Environmental Protection, Northeast Normal University, Changchun, China. E-mail fengj@nenu.edu.cn

Received 15 March 2011. Revision requested 14 June 2011.

Accepted 7 September 2011. First published online 17 July 2013.
Boyles et al., 2011; Kunz et al., 2011). However, populations of many bat species are declining because of threats such as climate change, habitat loss and degradation, hunting and emerging diseases (Meyer et al., 2010). Of these, habitat loss and degradation are the greatest threats to bats in most regions (Mickleburgh et al., 2002; Racey \& Entwistle, 2003; Jones et al., 2009; Kingston, 2010; Meyer et al., 2010).

Subterranean sites, such as caves and mines, provide roosts for many bat species (Kunz, 1982; Hutson et al., 2001), and some of the most important maternity and hibernating sites (Kunz, 1982; Kunz \& Lumsden, 2003; Murray \& Kunz, 2005). Such sites are also used as mating and aggregation locations for millions of individuals (Kunz, 1982; Hutson et al., 2001). The range and densities of bats that rely on caves are determined largely by the distribution, quantity and characteristics of available caves (Murray \& Kunz, 2005; Struebig et al., 2009). According to the IUCN Red List of Threatened Species (IUCN, 2010), 449 out of 1,132 extant bat species roost in caves and other subterranean habitats.

Disturbance of roosts threatens many bat species (Hutson et al., 2001), and declines of cave-dwelling bat populations were noted as early as 1952 (Mohr, 1972). Activities within or around caves, such as mining, quarrying, guano and bird nest collecting, caving, tourism, and deliberate or accidental disturbances can all have negative effects on bats (Hutson et al., 2001). In Mexico there have been dramatic declines of cave-dwelling bats caused by roost disturbance (Hutson et al., 2001) and in the USA roost disturbance was the cause of the decline of six threatened bat species (Elliott, 2000).

Currently, 121 bat species are known from China (IUCN, 2010). Although only one species (Pteropus lylei) is considered globally threatened, populations of 18 species are decreasing and the population trends of 79 species are unknown (IUCN, 2010). Sixty-two bat species are considered nationally threatened (Endangered, Vulnerable or Near Threatened; Wang \& Xie, 2004).

Despite the high proportion of nationally threatened bat species in China and the lack of information on the ecology of these species, little research has focused on bat conservation in the country (but see Niu et al., 2007). Based on our surveys of bats in 225 underground sites during 2003-2011 and an assessment of related social, economic and political issues, we recommend that protection of subterranean habitats should be a high priority for bat conservation in China. 


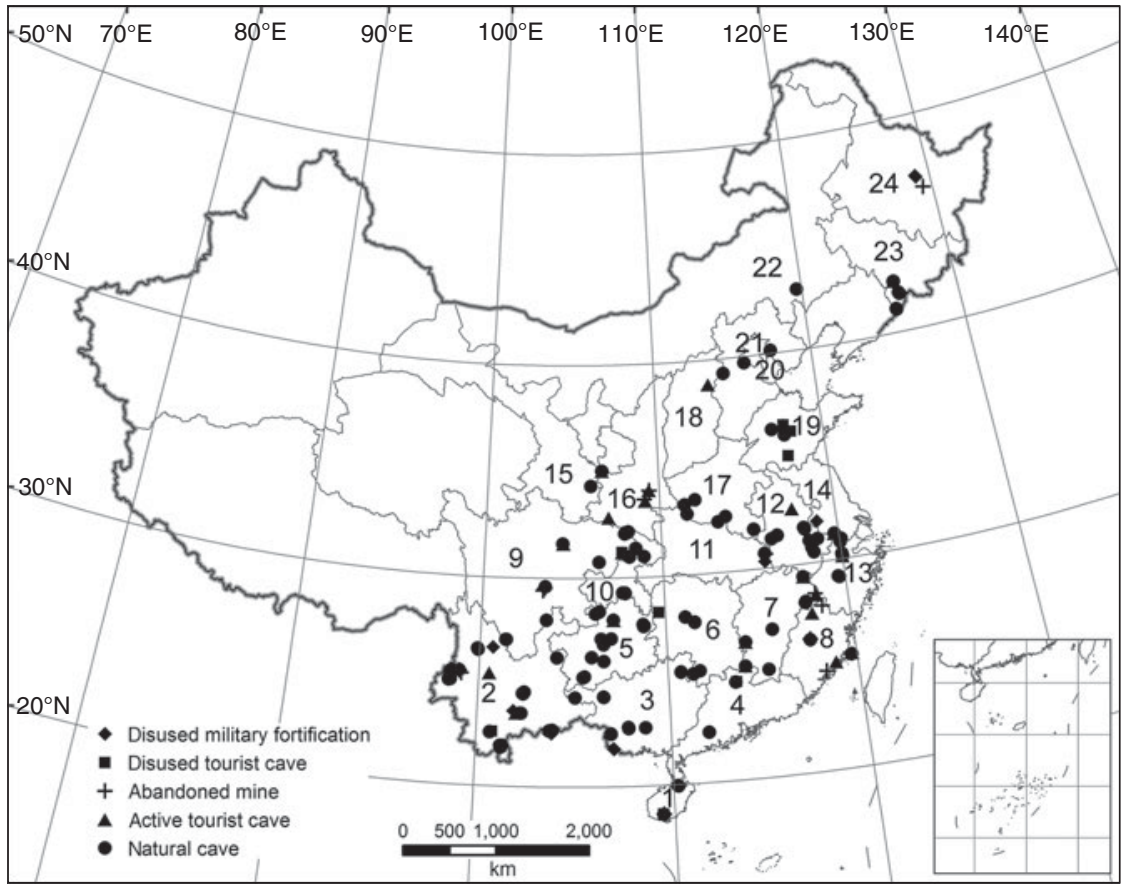

FIG. 1 China, showing the locations of potential bat roosts surveyed during 2003-2011. The provinces and municipalities where we surveyed are numbered: 1, Hainan; 2, Yunnan; 3, Guangxi; 4, Guangdong; 5, Guizhou; 6, Hunan; 7, Guangxi; 8, Fujian; 9, Sichuan; 10, Chongqing; 11, Hubei; 12, Anhui; 13, Zhejiang; 14, Jiangsu; 15, Gusu; 16, Shaanxi; 17 , Henan; 18, Shanxi; 19, Shandong; 20, Tianjin; 21, Beijing; 22, Neimenggu; 23, Jilin; 24, Heilongiiang.

\section{Methods}

We surveyed bats in 225 subterranean sites in China during March-August from 2003 to 2011 (Fig. 1). Information on roost localities was collected from the literature, Internet and local residents. Local people provided information on numbers of roost entrances, frequency of visits to the roost, identity of visitors, relative number of bats and safety issues. We entered roosts with torches, in the daytime, when the situation allowed. We recorded locations, with a global positioning system, and collected information on the freshness of bat faeces, traces of human activities, and roost and colony sizes. Colony size was assessed mainly by direct roost counts except for some inaccessible roosts, for which the colony sizes were estimated by evening emergence counts. Methods for estimation of colony size followed Kunz et al. (2009a).

Roost size was measured as the combined inner space size (in $\mathrm{m}^{3}$ ) of all chambers and passages of a cave. In most cases each chamber and passage was considered a cuboid and its volume determined as total length $\times$ mean height $x$ width. As the resulting estimates of roost size were not precise we identified roosts as large or small based on the median $\left(1,000 \mathrm{~m}^{3}\right)$ of the data. Additionally, if a roost was too large to be surveyed in 15-30 minutes it was regarded as large. A roost was categorized as inaccessible if its entrances were too small to allow a person to enter. The small percentage of roosts for which size could not be determined were categorized as data deficient.

Frequency of visitation to a roost was determined by interviewing elderly residents, wherever possible farmers who spent considerable time working outside throughout the year. Using the information gathered we categorized roosts as either visited or seldom visited. Seldom-visited roosts were those for which the residents questioned had not seen visitors in the previous 12 months. Within each roost that we could enter we searched for traces of human activities (e.g. footprints, food packages, cigarette butts, scratches, notches and remains of torches). If a roost was categorized as seldom visited and we found no obvious traces of human activities it was categorized as undisturbed, and otherwise as disturbed.

The conservation value of roosts was assessed using three criteria (species richness, abundance, and the presence of species of special concern) proposed by Arita $(1993,1996)$. Species of special concern were those categorized as Endangered or Vulnerable in China, or species endemic to China. We regard roosts that harbour $\geq 6$ species or $>1,000$ individuals as being of special concern.

Bat species were captured with ground-based mist nets set at entrances during emergence in the evening and sometimes in the early morning as bats returned from foraging. At least one person monitored the net, and when a bat entered it was removed with care to avoid any injury to either the bat or the handler (Kunz et al., 2009b). The handling of bats conformed to guidelines for animal care and use established by the American Society of Mammalogists (Gannon \& Sikes, 2007). All fieldwork abided by the Law of the People's Republic of China on Protection of Wildlife.

Most species were identified based on their morphological characteristics. For species that were ambiguous we carried out DNA-based phylogenetic analysis of one 3-mm diameter biopsy punch from the wing-membrane 


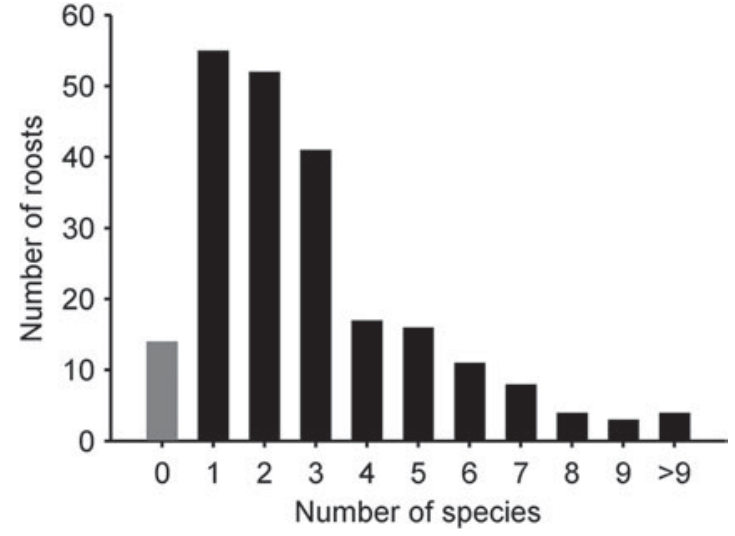

FIG. 2 The number of roosts (see Fig. 1 for locations) in the 225 subterranean sites located and surveyed that contained from $o$ to $>9$ species of bats.

per individual. For each captured bat we measured length of forearm, dorsal head and body length, and tail, ear, tibia and hind foot lengths (including claws, measured to the distal part of the claw) to an accuracy of $0.01 \mathrm{~mm}$, with digital callipers. Body mass was measured to the nearest $0.01 \mathrm{~g}$ with a digital balance. All bats were released after handling except for a small number of individuals of taxonomic interest (e.g. newly recorded species in China). For species newly recorded in China we took additional external measurements in the field and cranial and dental measurements in the laboratory. These bats were euthanized by intraperitoneal injection of sodium pentobarbital (80 $\mathrm{mg} \mathrm{kg}^{-1}$ ) in accordance with the American Veterinary Medical Association Guidelines on Euthanasia (AVMA, 2007), preserved in 75 or $95 \%$ ethanol and deposited in the Museum of Natural History of North-east Normal University, Jilin province, China.

To examine the potential effects of roost type (natural cave not developed for tourism, disused military fortification, active tourist cave, abandoned mine and disused tourist cave), roost size and human disturbance on species richness we used generalized linear modelling (GLM), with species richness as the dependent variable, roost type as a factor, and roost size and human disturbance as covariates. Only the main effects were considered, and the least significance difference method was used for pair-wise comparisons. Partial correlations were conducted to examine the relationship between the presence of species of special concern and roost type, roost size, human disturbance and species richness. We performed all statistical analyses with SPSS v. 19.0 (SPSS, Chicago, USA).

\section{Results}

In our surveys 57 bat species, in seven families, were found to roost in caves and other subterranean habitats. Of these,

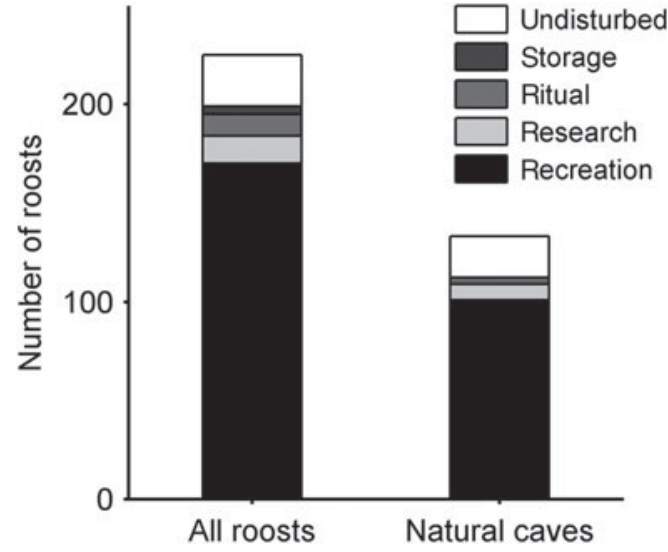

FIG. 3 The main human activities observed at the sites of the 225 bat roosts surveyed (Fig. 1), for all roosts combined and for those in natural caves undeveloped for tourism. Storage indicates sites used to store items such as firewood. Ritual indicates sites used for ritualistic or religious purposes.

11 species had not previously been documented to roost in caves (on either the China Species Red List or the IUCN Red List; Wang \& Xie, 2004; IUCN, 2010) and six species are endemic to China (Supplementary Table S1; for specimens collected see Supplementary Table S2). The number of species in occupied roosts was $1-15$ but only c. $10 \%$ of these roosts harboured $\geq 6$ species; $75 \%$ contained $\leq 4$ species (Fig. 2, Supplementary Table $S_{3}$ ).

Our literature search indicated that a further six bat species have been documented using caves for roosting in China. Combining information from the China Species Red List (Wang \& Xie, 2004), the IUCN Red List (IUCN, 2010) and bat species recorded in our survey and by other researchers, we determined that a total of 101 bat species $(77 \%)$ are roosting in caves and other subterranean habitats in China (including Taiwan). This includes 30 nationally Endangered or Vulnerable species (Wang \& Xie, 2004), and nine endemic species (Supplementary Table $\mathrm{S}_{1}$ ).

Of the 225 underground sites we surveyed, there were 133 natural caves not developed for tourism, 34 disused military fortifications, 34 active tourist caves, 13 abandoned mines and 11 disused tourist caves. Almost 90\% of the sites were disturbed and only $15 \%$ of the natural caves were free of disturbance (Fig. 3). Up to $46 \%$ of sites harboured threatened or endemic species, 30 sites harboured $\geq 6$ species and 25 sites contained $>1,000$ individuals, giving a total of 121 roosts that warrant special consideration for protection (Supplementary Table $S_{3}$ ). Recreation was the most common cause of disturbance, affecting $85 \%$ of the disturbed roosts and $90 \%$ of the disturbed caves (Fig. 3).

Results of the GLM revealed that species richness was positively correlated with roost size $\left(\chi^{2}=22.75, \mathrm{df}=1\right.$, $\mathrm{P}<0.001)$ but negatively correlated with human disturbance $\left(\chi^{2}=7.05, \mathrm{df}=1, \mathrm{P}<0.01\right)$. Large roosts contained a mean of 3.29 species and small roosts a mean of 2.17 species 
(least significance difference comparison, $\mathrm{P}<0.001$ ). Twenty-three of the 25 roosts with $>1,000$ individuals were large roosts. Disturbed roosts contained a mean of 2.59 species whereas undisturbed roosts had a mean of 3.86 species (least significance difference comparison, $\mathrm{P}<0.05)$. Roost type had a strong effect on species richness $\left(\chi^{2}=17.56, \mathrm{df}=4, \mathrm{P}<0.01\right)$. Caves formerly used for tourism contained a mean of 4.78 species whereas abandoned mines contained a mean of 1.83 species (least significance difference comparison, $\mathrm{P}<0.001)$. However, other pairwise comparisons indicated that species richness did not differ significantly between roosts in abandoned mines, active tourist caves, disused military fortifications or natural caves (least significance differences, all $\mathrm{P}>0.05$ ).

Partial correlations indicated that the presence of threatened and endemic species was positively correlated with species richness $(\mathrm{P}<0.001)$ and negatively correlated with roost disturbance $(\mathrm{P}<0.05)$. The presence of species of special concern was not directly correlated with roost size $(\mathrm{P}=0.30)$ or roost type $(\mathrm{P}=0.68)$.

\section{Discussion}

Seventy-seven percent (101 of 131) of the bat species in China, including 30 species categorized nationally as Endangered or Vulnerable and nine endemic species, have been documented to roost in caves and other subterranean habitats for at least part of each year, with some roosts harbouring up to 15 species. The total number of bat species is a combination of the number of species recognized by IUCN (except Pipistrellus alaschanicus, which has been renamed Hypsugo alaschanicus, Horáček et al., 2000; and Rhinolophus rouxii, which may be the same species as Rhinolophus sinicus, Zhang et al., 2009) and 12 species recorded recently (Zhang et al., 2007, 2010; Feng et al., 2008; Sun et al., 2008; Wu et al., 2008; Kuo et al., 2009; Zhou et al., 2009; Jiang et al., 2010; Wang et al., 2010; Wu \& Thong, 2011).

Our results showed that undisturbed roosts supported a greater number of bat species than disturbed roosts and that species of special concern were more commonly found in roosts devoid of human disturbance. This has important implications for bat conservation in China given that $77 \%$ of the bat species roost in subterranean sites but that only about $10 \%$ are free of human disturbance. Disturbance of roosts by recreational activities could cause severe problems for bats, which can be woken by human noise in the day (Mann et al., 2002) and affected indirectly by changes in aspects of cave microclimate such as carbon dioxide concentration, temperature and humidity (Pulido-Bosch et al., 1997; Gunn, 2004).

Research activities in caves in China are increasing. For example, there were only a few people studying bats at the end of the 2oth century but there are now at least five research groups studying bats in mainland China (J. Feng, pers. comm.). Although this could improve our understanding of cave ecosystems it could also be a new threat to bats and other cave-obligate organisms if researchers are not sufficiently aware of the conservation considerations required when working in caves. Research activities can cause declines in bat colony sizes, depending on the intensity and frequency of disturbance (Hayes et al., 2009). As most researchers are generally interested in their own research subjects, researchers studying cave fauna other than bats can unintentionally pose potential threats to bats, and vice versa.

Based on the criteria of Arita $(1993,1996), 121$ of the 225 roosts examined deserve special consideration for protection. In general, larger roosts merit greater conservation concern because they support more bat species and greater numbers of individuals than smaller roosts. The absence of a correlation between roost size and the presence of species of special concern suggests that a conservation plan based solely on roost size would not be adequate for the protection of the cave bats of China. The greater number of species of bats in disused tourist caves indicates that this type of roost also deserves greater conservation attention. Improperly installed gates, for example, could cause species to lose their preferred roosts.

Prioritization is essential to minimize biodiversity loss because the location of and threats to biodiversity are distributed unevenly (Brooks et al., 2006). Our results suggest that protection of subterranean habitats should be a high priority for bat conservation in China. Up to $46 \%$ of the roosts surveyed harboured either threatened or endemic species of bats (i.e. those that are most critical indicators of conservation concern; Brooks et al., 2006; Miller et al., 2006) and, although $77 \%$ of bat species in China rely on underground roosts, only $10 \%$ of these were free of human disturbance. Awareness of cave ecosystems and cave-dwelling species in China is poor, not only among the public but also among some government managers and researchers (Whitten, 2009; Zhang et al., 2009). An increasing number of caves in China continue to be exploited for tourism without prior environmental impact assessments (Song et al., 2004). By $2005>400$ caves in China had been developed for tourism (Wu \& Zhuang, 2007) but there is no government agency or conservation NGO directly concerned with caves (Whitten, 2009). Any person, whatever their occupation, age or intention, may visit any cave without restriction.

Our findings indicate that prioritization of the protection of underground habitats for bats in China is warranted. For the development of management guidelines and policies, however, more ecological data on bats and caves are required, with an emphasis on population assessment and monitoring. To support this we are now actively communicating with government managers responsible for wildlife 
conservation and cave resource management by sharing our data with them. We recommend that bat researchers and other researchers specializing in caves should promote the conservation of cave ecosystems in China.

\section{Acknowledgements}

This study was financed by the National Natural Science Foundation of China (grants 31030011, 30870371, 30900166) and Fundamental Research Funds for the Central Universities (No. 10SSXT128). We are grateful to Limin Shi, Longru Jin, Sen Liu, Aiqing Lin, Keping Sun, Ying Liu, Genxian Ye, $\mathrm{Xu}$ Zhu, Shi $\mathrm{Li}$ and Yunjiao Zhao for their assistance in the field. We would also like to thank Tom Kunz and an anonymous reviewer for helpful comments.

\section{References}

Arita, H.T. (1993) Conservation biology of the cave bats of Mexico. Journal of Mammalogy, 74, 693-702.

Arit A, H.T. (1996) The conservation of cave-roosting bats in Yucatan, Mexico. Biological Conservation, 76, 177-185.

AVMA (2007) AVMA Guidelines on Euthanasia. Http://www.avma. org/issues/animal_welfare/euthanasia.pdf [accessed 1 July 2011].

Betke, M., Hirsh, D.E., Makris, N.C., McCracken, G.F., Procopio, M., Hristov, N.I. et al. (2008) Thermal imaging reveals significantly smaller Brazilian free-tailed bat colonies than previously estimated. Journal of Mammalogy, 89, 18-24.

Boyles, J.G., Cryan, P.M., McCracken, G.F. \& Kunz, T.H. (2011) Economic importance of bats in agriculture. Science, 332, 41-42.

Brooks, T.M., Mittermeier, R.A., Da Fonseca, G.A.B., Gerlach, J., Hoffmann, M., Lamoreux, J.F. et al. (2006) Global biodiversity conservation priorities. Science, 313, 58-61.

Cleveland, C.J., Betke, M., Federico, P., Frank, J.D., Hallam, T.G., Horn, J. et al. (2006) Economic value of the pest control service provided by Brazilian free-tailed bats in southcentral Texas. Frontiers in Ecology and the Environment, 4, 238-243.

Elliott, W.R. (2000) Conservation of the North American cave and karst biota. In Ecosystems of the World: Subterranean Ecosystems (eds H. Wilkens, D.C. Culver \& W.F. Humphreys), pp. 665-69o. Elsevier, Amsterdam, Netherlands.

FenG, Q., LI, S. \& WANG, Y. (2008) A new species of bamboo bat (Chiroptera: Vespertilionidae: Tylonycteris) from southwestern China. Zoological Science, 25, 225-234.

Gannon, W.L. \& Sikes, R.S. (2007) Guidelines of the American Society of Mammalogists for the use of wild mammals in research. Journal of Mammalogy, 88, 809-823.

GunN, J. (ed.) (2004) Encyclopedia of Caves and Karst Science. Routledge, New York, USA.

Hayes, J.P., Ober, H.K. \& Sherwin, R.E. (2009) Survey and monitoring of bats. In Ecological and Behavioral Methods for the Study of Bats (eds T.H. Kunz \& S. Parsons), pp. 112-129. Johns Hopkins University Press, Baltimore, USA.

Horáček, I., Haná, V. \& Gaisler, J. (2000) Bats of the Palearctic region: a taxonomic and biogeographic review. In Proceedings of the VIIIth European Bat Research Symposium. Vol. 1. Approaches to Biogeography and Ecology of Bats (ed. B. W. Woloszyn), pp. 11-157. Institute of Systematics and Evolution of Animals, Krakow, Poland.
Hutson, A.M., Mickleburgh, S.P. \& Racey, P.A. (eds) (2001) Microchiropteran Bats: Global Status Survey and Conservation Action Plan, IUCN, Gland, Switzerland, and Cambridge, UK.

IUCN (2010) 2010 IUCN Red List of Threatened Species. IUCN, Gland, Switzerland and Cambridge. Http://www.iucnredlist.org [accessed 7 December 2010].

Jiang, T., Sun, K., Chou, C., Zhang, Z. \& FenG, J. (2010) First record of Myotis flavus (Chiroptera: Vespertilionidae) from mainland China and a reassessment of its taxonomic status. Zootaxa, 2414, 41-51.

Jones, G., Jacobs, D., Kunz, T., Willig, M. \& Racey, P. (2009) Carpe noctem: the importance of bats as bioindicators. Endangered Species Research, 8, 93-115.

Kalka, M.B., Smith, A.R. \& Kalko, E.K.V. (2008) Bats limit arthropods and herbivory in a tropical forest. Science, 320, 71.

Kingston, T. (2010) Research priorities for bat conservation in Southeast Asia: a consensus approach. Biodiversity and Conservation, 19, 471-484

KunZ, T.H. (1982) Roosting ecology of bats. In Ecology of Bats (ed. T.H. Kunz), pp. 1-55. Plenum Press, New York, USA.

Kunz, T.H., Betke, M., Hristov, N.I. \& Vonhof, M.J. (2009a) Methods for assessing colony size, population size, and relative abundance of bats. In Ecological and Behavioral Methods for the Study of Bats (eds T.H. Kunz \& S. Parsons), pp. 133-157. Johns Hopkins University Press, Baltimore, USA.

Kunz, T.H., De Torrez, E.B., Bauer, D., Lobova, T. \& FLEMING, T.H. (2011) Ecosystem services provided by bats. Annals of the New York Academy of Sciences, 1223, 1-38.

Kunz, T.H., Hodgrison, R. \& Weise, C.D. (2009b) Methods of capturing and handling bats. In Ecological and Behavioral Methods for the Study of Bats (eds T.H. Kunz \& S. Parsons), pp. 3-35. Johns Hopkins University Press, Baltimore, USA.

KunZ, T.H. \& Lumsden, L.F. (2003) Ecology of cavity and foliage roosting bats. In Bat Ecology (eds T.H. Kunz \& M.B. Fenton), pp. 3-89. University of Chicago Press, Chicago, USA.

Kuo, H., Fang, Y., Csorba, G. \& Lee, L. (2009) Three new species of Murina (Chiroptera: Vespertilionidae) from Taiwan. Journal of Mammalogy, 90, 980-991.

Lobova, T.A., Geiselman, C.K. \& Mori, S.A. (2009) Seed Dispersal by Bats in the Neotropics. Botanical Garden, New York, USA.

Mann, S., Steidl, R. \& Dalton, V. (2002) Effects of cave tours on breeding Myotis velifer. The Journal of Wildlife Management, 66, 618-624.

Meyer, C.F.J., Aguiar, L.M.S., Aguirre, L.F., Baumgarten, J., Clarke, F.M., Cosson, J.F. et al. (2010) Long-term monitoring of tropical bats for anthropogenic impact assessment: gauging the statistical power to detect population change. Biological Conservation, 143, 2797-2807.

Mickleburgh, S.P., Hutson, A.M. \& Racey, P.A. (2002) A review of the global conservation status of bats. Oryx, 36, 18-34.

Miller, R.M., Rodríguez, J.P., Aniskowicz-Fowler, T., Bambaradeniya, C., Boles, R., Eaton, M.A. et al. (2006) Extinction risk and conservation priorities. Science, 313, 441.

Moнr, C.E. (1972). The status of the threatened species of cave-dwelling bats. Bulletin of the National Speleological Society, $34,33-47$.

Murray, S.W. \& Kunz, T.H. (2005) Bats. In Encyclopedia of Caves (eds D. Culver \& W. White), pp. 39-45. Academic Press, London, UK.

Niu, H., Wang, N., Zhao, L. \& LiU, J. (2007) Distribution and underground habitats of cave dwelling bats in China. Animal Conservation, 10, 470-477.

Pulido-Bosch, A., Martin-Rosales, W., López-Chicano, M., Rodriguez-Navarro, C.M. \& Vallejos, A. (1997) Human 
impact in a tourist karstic cave (Aracena, Spain). Environmental Geology, 31, 142-149.

Racey, P.A. \& Entwistle, A.C. (2003) Conservation ecology of bats. In Bat Ecology (eds T.H. Kunz \& M.B. Fenton), pp. 680-743. University of Chicago Press, Chicago, USA.

Song, L., Wang, J., Liang, F., Wei, X. \& Lin, J. (2004) Effect of human and natural factors on the environment of show caves. Carsologica Sinica, 23, 91-98.

Struebig, M.J., Kingston, T., Zubaid, A., Le Comber, S.C., Mohd-Adnan, A., Turner, A. et al. (2009) Conservation importance of limestone karst outcrops for Palaeotropical bats in a fragmented landscape. Biological Conservation, 142, 2089-2096.

Sun, K., Feng, J., Jiang, T., Ma, J., Zhang, Z. \& Jin, L. (2008) A new cryptic species of Rhinolophus macrotis (Chiroptera: Rhinolophidae) from Jiangxi Province, China. Acta Chiropterologica, 10, 1-10.

Wang, L., Jiang, T., Sun, K., Wang, Y., Tiunov, M.P. \& Feng, J. (2010) Morphological description and taxonomical status of Myotis petax. Acta Zootaxonomica Sinica, 35, 360-365.

Wang, S. \& XIE, Y. (2004) China Species Red List, Volume 1: Red List. Higher Education Press, Beijing, China.

Whitten, T. (2009) Applying ecology for cave management in China and neighbouring countries. Journal of Applied Ecology, $46,520-523$.

Wu, W. \& ZhUanG, Z. (2007) The sustainable development of mature tourism cave: the case study of Anhui Jiushan Cave. Journal of Guilin Institute of Tourism, 18, 378-382.

Wu, Y., Motokawa, M. \& Harada, M. (2008) A new species of horseshoe bat of the genus Rhinolophus from China (Chiroptera: Rhinolophidae). Zoological Science, 25, 438-443.

Wu, Y. \& Thong, V.D. (2011) A new species of Rhinolophus (Chiroptera: Rhinolophidae) from China. Zoological Science, 28, 235-241.
Zhang, J., Han, N., Jones, G., Lin, L., ZhanG, J., Zhu, G. et al. (2007) A new species of Barbastella (Chiroptera: Vespertilionidae)from North China. Journal of Mammalogy, 88, 1393-1403.

Zhang, L., Jones, G., Zhang, J., Zhu, G., Parsons, S., Rossiter, S.J. et al. (2009) Recent surveys of bats (Mammalia: Chiroptera) from China. I. Rhinolophidae and Hipposideridae. Acta Chiropterologica, $11,71-88$.

Zhang, L., Gong, Y., Zhu, G., Hong, T., Zhao, X. \& Mao, X. (2010) New record of a bat species from China, Megaderma spasma (Linnaeus, 1758). Zoological Research, 31, 328-332.

ZhanG, L., ZhU, G., Jones, G. \& ZhaNG, S. (2009) Conservation of bats in China: problems and recommendations. Oryx, 43 , 179-182.

Zhou, Z., Guillén Servent, A., Lim, B.K., Eger, J.L., Wang, Y. \& JIANG, X. (2009) A new species from southwestern China in the Afro-Palearctic lineage of the horseshoe bats (Rhinolophus). Journal of Mammalogy, 90, 57-73.

\section{Biographical sketches}

JINHONG LUO studies the conservation biology and sensory ecology of bats. Currently he is investigating the impacts of climate change, noise pollution and roost disturbance on bats. TINGLEI JIANG specializes in the taxonomy of Chinese bats and works on geographical variation in echolocation calls. GUANJUN LU and LeI WANG are working, respectively, on the phylogeography and echolocation behaviours of bats, and both have interests in the taxonomy of Chinese bats. JING WANG studies the habitat selection of bats, with a special interest in understanding the effects of human activities on habitat use by horseshoe bats. JIANG FENG carried out some of the earliest research on the echolocation behaviour of bats in China. Currently, he leads a large research group studying the evolutionary biology, behaviour ecology and conservation biology of bats. 